\title{
Cortisol, Temperament and Serotonin in Karate Combats: An Evolutionary Psychobiological Perspective
}

\author{
Davide Ponzi, et al. [full author details at the end of the article]
}

Received: 30 June 2021 / Revised: 20 September 2021 / Accepted: 21 September 2021 /

Published online: 4 October 2021

(C) The Author(s) 2021

\begin{abstract}
Objectives There is evidence suggesting that in martial arts competitions athletes characterized by higher anxiety and harm avoidance may be more likely to lose a fight. This psychological profile has been hypothesized to explain in part the observation that cortisol is higher in losers before and in response to a competition. An important research target that needs further exploration is the identification of phenotypic traits that can be helpful in predicting athletes' performance. Here we present a brief description of the theoretical bases that drives our research in the evolutionary psychobiology of sports and illustrate preliminary data on the relationship between the 5HTTLPR genotype, salivary cortisol, temperament and competition.

Methods Sixty-five healthy male non-professional athletes provided saliva samples 10 min before and after a kumite session and filled out the Tridimensional Personality Questionnaire.

Results Salivary cortisol levels $10 \mathrm{~min}$ before the competition were higher in losers and in athletes with the $S$ allele. Temperament was associated with competition outcome and cortisol: losers were characterized by higher scores of harm avoidance and harm avoidance was positively correlated with cortisol levels.

Conclusions The results confirm previous findings linking temperamental traits, pre-and post- competition physiological stress response with competition outcome in kumite fight. Moreover, they indicate an association between the 5HTTLPR polymorphism and pre-competition salivary cortisol, thus providing a preliminary but non-conclusive evidence on the role played by the 5HTTLPR genotype as a vulnerability factor in sport competition.
\end{abstract}

Keywords Cortisol · Temperament $\cdot$ Serotonin transporter $\cdot$ Evolutionary psychobiology $\cdot$ Sports science

Harold Dadomo and Laura Filonzi have contributed equally 


\section{Introduction}

From a Darwinian perspective sports can be considered a ritualized form of within- and between-group competition (Goodwin, 2008; Lombardo, 2012). As with other forms of ritualized behavior, the meaning of the behavior is detached from its original evolved functions, becoming an adaptive exaptation (Lombardo, 2012): players of a baseball team competing for the Major League Baseball do not certainly look like bands of warriors trying to seize an enemy camp. Likewise, Judo fighters are not competing for access to primary resources such as food or mates. Nonetheless, if modern culturally modulated sport activities are evolutionarily linked to ancestral intraspecific forms of competition, then athletes that succeed in sports should be characterized by a mix of morphological, physiological and psychological traits that provided our ancestors with a performance edge over competitors during fitness relevant contests (hunting, fighting, warfare etc.).

Through the evolutionary lenses, the study of sports performance can advance our understanding of how the human body and psyche work, their evolutionary history and their capacity for adaptation to new physical and social environments (Bramble \& Lieberman, 2004; Longman et al., 2020). For example, individual differences in body shape, that cluster in ecogeographical clines and that are thought to have evolved for improved thermoregulation at different latitudes, are linked to performance in long distance runners (Longman et al., 2019, 2021). The specific morphology and musculature of the shoulder girdle of modern men, which is thought to have evolved under the selective pressure of hunting and warfare because it provided improved abilities in throwing projectiles, are now key for success in throwing sports and for understanding its evolutionary origins among different species of hominins (Lombardo \& Deaner, 2018; Longman et al., 2020; Shaw \& Stock, 2009).

Given the recent invention of modern sports, some disciplines may not require any specific evolved physical traits, that is, the evolutionary approach to sports science may be especially useful for those sports where physiological and morphological traits required also in foraging or fighting are necessary for success. However, all modern sports share a common denominator: competition for winning. This fact should give psychological mechanisms an important spotlight when studying the evolutionary function of performance.

We argue that in the field of sports science the psychobiological functions that have evolved to face and deal with the complex social dynamics of competition have not been thoroughly analyzed from an evolutionary perspective. The way people cope with the challenges derived from conflicts with conspecifics over primary and secondary resources is strictly related to their performance in such contests. It is argued that coping with social competition had fitness relevant consequences (i.e. survival and social status) during our evolutionary history (Salvador \& Costa, 2009). This implies that successful athletes should be characterized by a better ability to deal with the psychological and physiological costs of competition. However, it is now clear that even in the population of professional athletes the effects of competition is linked with risks and costs for mental health (Reardon et al., 2019). 


\section{The Evolutionary Psychobiology of Sports Performance}

In our laboratory we have focused on the role played by the psychobiological stress response during sports competition for more than a decade (Filonzi et al., 2015; Parmigiani et al., 2006, 2009). We chose to focus on stress because a stressful event is characterized by uncontrollability and unpredictability (Koolhaas et al., 2011); by fulfilling these criteria, sport competitions can be considered elicitors of the psychosocial stress response (Salvador \& Costa, 2009). Individual differences in appraisal, personality and neuroendocrine traits that can influence athletes' interpretation of a competitive event affect their performance and post-performance psychological wellbeing (Behnke \& Kaczmarek, 2018; Blascovich et al., 2004; Hase et al., 2019; Jones et al., 2009; Meijen et al., 2020; Petito et al., 2016).

In line with evolutionary models developed within the field of behavioral ecology, one question we seek to answer is if differences between athletes in the behavioral response to stress are in fact the results of evolutionary processes (Caramaschi et al., 2014; Koolhaas et al., 1999, 2007, 2011; Korte et al., 2005). We seek to understand if different traits composing the human phenotype have been designed by natural selection to covary in ways that improve performance under stress. Related to that, we are also interested in uncovering the trade-offs between traits that may be related to vulnerabilities to stress (Geary, 2016) within the sports context. In short, the goal of our line of research is to better characterize athletes in terms of attitude, performance and well-being using an evolutionary framework.

In our previous work we have found that different facets of temperament and personality correlate with physiological and performance outcomes in judo and karate non-professional athletes (Parmigiani et al., 2006, 2009). Successful athletes, as determined by winning a fight, were characterized by higher levels of novelty seeking and lower levels of harm avoidance and athletes with higher scores of harm avoidance had also higher levels of cortisol before the competition. Harm avoidance is a temperamental trait that may predispose individuals to experience psychological distress, fear, anxiety and low mood (Farmer \& Seeley, 2009; Trouillet \& Gana, 2008). In fact people that score high in harm avoidance are usually described as pessimistic thinkers and with a tendency to anticipate pain and failure (Hruby et al., 2010; Quilty et al., 2010).

These results were suggestive of the possibility that athletic performance could be predicted by clusters of correlated psychological and physiological traits. Especially interesting was the similarity of our results with those revealing the role played by individual differences in behavioral coping strategies and emotional reactivity, such as exploration vs. risk assessment; boldness vs. shyness; fearfulness vs. aggressiveness observed during agonistic aggression and in relation to victory/defeat reported in non-human animal studies (Bartolomucci et al., 2005; Blanchard \& Blanchard, 2003; Øverli et al., 2007; Parmigiani et al., 2009; Sgoifo et al., 2005).

These works show that individual predispositions and their associated (neuro)biological traits (high vs. low testosterone; high vs. low Hypothalamus-Pituitary-Adrenal (HPA) axis reactivity; high vs. low fight or flight response) predict an animal's probability of success in dyadic agonistic encounters (Korte e et al., 2005; Øverli et al., 2007). The parallels between non-human animals and our previous results 
suggest the possibility of a mechanism conserved across species for dealing with intraspecific agonistic challenges. An important consequence is that the evolutionary approach could be used to predict those traits that improve performance but, concomitantly, risks and vulnerability to stress related disorders.

\section{The Present Study}

Physiologically, athletes' response to a competition is linked to the activation of the stress system, represented by the sympathetic nervous system and the HPA axis. The HPA axis response during a competition is adaptive insofar as cortisol, the end-product of the HPA axis, increases the amount of glucose needed for muscle metabolism and for energetic recovery after a stressful event has finished (Sapolsky et al., 2000). As a consequence, cortisol levels increase in response to sport competition independently of the outcome (Casto \& Edwards, 2016a; Filaire et al., 2009; Jiménez et al., 2012; Slimani et al., 2018). However, high cortisol levels are associated with anxiety, especially if athletes show negative appraisal and perceive the competition as a stressful event (Filaire et al., 2001; Salvador et al., 2003) and cortisol changes in response to competition occur also in the absence of physical stress (Zilioli \& Watson, 2013). Thus, cortisol levels before and after the competition could be used to capture also non-physical, psychological factors which in turn could be linked to victory or defeat (Casto \& Edwards, 2016b; Salvador \& Costa, 2009).

Competition outcome appears to affect cortisol differently, with winners showing decreases of cortisol while increases are observed in losers (Filaire et al., 2009; Jiménez et al., 2012; Parmigiani et al., 2006, 2009), with some exceptions (Filaire et al., 2001; Ouergui et al., 2016). Likewise, a direct relationship between pre-competition cortisol levels and competition outcome in martial arts is far from being conclusive, with some studies showing that winners have higher pre-competition cortisol levels (Papacosta et al., 2016; Salvador et al., 2003) and others showing no differences or the opposite relationship (Cintineo \& Arent, 2019; Filaire et al., 2001). Nonetheless, in line with the animal literature on evolved behavioral coping styles, there is some evidence suggesting that pre-competition levels of cortisol are high in losers that are characterized by higher harm avoidance, anxiety and insecurity (Cintineo \& Arent, 2019; Parmigiani et al., 2009).

Consistently with our previous research, here we present preliminary data from a pilot study on cortisol, the serotonin transporter linked polymorphic promoter region (5-HTTLPR) polymorphism and temperament in response to a Karate kumite, a dyadic regulated sporting ritualized fight. Drawing from the evolutionary animal literature, we explored the possibility that these different psychobiological traits could distinguish winners from losers, that is, that losers should be characterized by a set of traits typical of a reactive coping strategy: harm avoidance and higher HPA response (Parmigiani et al., 2006, 2009). We focused on the 5-HTTLPR polymorphism because of its involvement in anxiety, harm avoidance, neuroticism and stress response in sports: there are some hints suggesting a higher frequency of the LL genotype in athletes (çorak et al., 2017; Sysoeva et al., 
2009) and an association between the 5HTTLPR with neuroticism and sport anxiety (Petito et al., 2016; Sanhueza et al., 2016).

\section{Materials and Methods}

\section{Participants}

Participants were sixty-five healthy male Karate fighters aged 18-44 years $(\mathrm{M}=28.35, \mathrm{SD}=7.18)$, were not currently on any medication or hormone therapies and di not present history of psychological disorders, with technical abilities ranging from brown to black belt, an average of 8-10 h of training per week and with experience at the competitive level. Their body weights ranged between 64 and $98 \mathrm{~kg}(\mathrm{M}=76, \mathrm{SD}=4.8)$, with a $\mathrm{BMI}$ ranging between 20 and 27. The participants were recruited from two martial arts Clubs in the Parma area (Northern Italy). The study was performed in accordance with the ethical standards of the Helsinki Declaration and all participants provided a signed informed consent before participating in the study, previously approved by the Ethics Committee of the School of Medicine of the University of Parma. The study purpose and protocol were clearly explained to the participants. Only athletes who agreed to participate in the study were assessed. To guarantee subject privacy, an alphanumeric code was used for individual identification. Of the 65 athletes that participated in the contest, only 46 gave consent for hormonal and genetic analysis while everyone gave consent for personality measurements, but of them only 56 returned the questionnaires. Thus, sample size varies between tests.

\section{Kumite Session}

Following the methodology used by Parmigiani et al (2009), with the help of Karate masters participants, compatitors were allocated in symmetric dyads, matched for weight and technical ability. To avoid both familiarity between the fighters and the "home advantage", each member of the dyad belonged to a different sports club (according to the martial arts practice this is called "dojo") and sessions occurred in a neutral arena (i.e. a "dojo" of a different sport club unfamiliar to participants). Every participant took part in a single symmetrical contest confrontation with a maximum duration of $3 \mathrm{~min}$. Using the international rules of the World Karate Federation (WKF), each master of the two clubs alternately refereed and judged the fights. Although the Karate contest session is a free fight, it is a regulated sporting activity in which ritualization is always the rule (i.e. the hits in terms of kicks and punches should stop before hitting the target and thus the most dangerous and deadly techniques are banned). The winner was the athlete who successfully delivered the greater numbers of hits to the opponent and thus achieved the higher score. 


\section{Saliva Collection and Analysis}

In order to avoid confounding effects on the hormonal levels and minimize variability in neuro-endocrine circadian rhythms, Kumite sessions were carried out between 6:00 and 9:00 p.m. A saliva sample for cortisol analysis and a buccal swab for genetic analysis were collected from each member of the dyad $10 \mathrm{~min}$ before and 10 min after the kumite session. Saliva samples were collected using Salivette cotton rolls and using Salivette cortisol polypropylene rolls (Sarstedt, Nümbrecht, Germany). Salivette rolls were chewed for $1 \mathrm{~min}$ and then placed into centrifugation tubes. After centrifugation at $3000 \mathrm{xg}$ for $15 \mathrm{~min}$, supernatants from whole saliva samples and saliva samples from both Salivette types were transferred into deep-well plates and stored frozen at $-20^{\circ} \mathrm{C}$. Before further analysis, samples were thawed and centrifuged again at $3000 \mathrm{xg}$ for $15 \mathrm{~min}$. Cortisol was determined by Radioimmunoassay I ${ }^{125}$ (Radim, Rome, Italy). All samples were treated in duplicate in the same assay. The intra- and inter-assay variation coefficients were $3.9 \%$ and $9.0 \%$ and sensitivities was $0.9 \mu \mathrm{g} / \mathrm{l}$.

\section{HTT Molecular Analysis}

Genomic DNA was extracted and purified from saliva samples using the MasterAmp Buccal Swab DNA Extraction Kit (Tebu-bio, Milan, Italy). Polymorphisms of the promoter region of the serotonin transporter 5HTT (5-hydroxytryptamine transporter also known as serotonin transporter) were investigated using specific primers for 5HTTLPR suggested by Gelernter et al. (1999): forward 5'-ATGCCAGCACCT AACCCCTAATGT-3', and reverse 5'-GGACCGCAAGGTGGGCGGGA-3'. PCR amplification conditions (thermal cycler MJ Research PTC100, Waltham, MA) were previously described by Nonnis Marzano et al. (2008). PCR products were separated by $2.5 \%$ agarose gel electrophoresis followed by ethidium bromide staining and visualized under UV light. Alleles Long (L) and Short (S) were identified using the GeneRuler 100 bp DNA ladder (Fermentas, Hanover, MD, USA). Quality control of data was assessed with bimonthly intercalibration with similar laboratories. An additional percentage of $20 \%$ of analyses were randomly repeated to verify data reproducibility. No discrepancies were observed.

\section{Temperament}

The Tridimensional Personality Questionnaire, TPQ (Cloninger et al., 1991), is a 100-item self-report questionnaire that assesses three personality dimensions: novelty seeking, reward dependence, and harm avoidance. The dimensions describe basic patterns of the adaptive response to specific classes of environmental stimuli and are hypothesized to be genetically independent. Three dimensions of intra- and interpersonal functioning are measured by the TPQ: (a) Novelty Seeking (NS; 34 items), (b) Harm Avoidance (HA; 33 items), and (c) Reward Dependence (RD; 33 items). The primary factors of the TPQ can be assessed at two levels of analysis: (a) three higher-order factor scales, or (b) eleven lower-order scales. The higher-order 
scales are unit weighted sums of the lower-order scales. Four scales define the Novelty Seeking factor: (NS1) Exploratory versus Rigid, (NS2) Impulsive versus Reflective, (NS3) Extravagant versus Frugal, (NS4) Disorderly versus Regimented. Four lower-order scales define Harm Avoidance: (HAI) Anticipatory worry versus Optimism, (HA2) Tension about uncertainty or physical danger, (HA3) Shyness with strangers, and (HA4) Fatigability and asthenia. Following Otter et al. (Otter et al., 1995), three lower-order scales were used to define Reward Dependence: (RDI) Social Sensitivity versus Detachment, (RD3) Attachment versus detachment, (RD4) Dependence versus independence. The TPQ has been reported to be a valid and reliable measure based on normative data from an Italian sample of 270 adults. Alpha coefficients for the TPQ scales sample range from 0.61 to 0.85 and are consistent across demographic groups; test-retest correlations range from 0.70 to 0.79 . For the present study, the Italian version of the TPQ was used (Manfredonia et al., 1991; Rossi et al., 1996) and participants returned the questionnaire 15 days after the end of the fight.

\section{Results}

Cortisol data was transformed via a $\log 10$ transformation to adjust for positive skew. Data are presented as mean \pm SD. See Table 1 for descriptive statistics of key variables. All statistical analyses were performed using SPSS 25 (IBM). Pre-competition or post-competition scores of cortisol that were outliers (more than $3 \mathrm{SD}$ above the mean) were winsorized to the next highest value (1.5 SD) (Wilcox, 2010). A preliminary analysis of the differences in pre-competition levels of cortisol between losers and between genotypes were analyzed by means of Student's t-test with Bonferroni's followed by Student's t-test with Bonferroni's, and Welch's correction when required.

\section{Relationship Between Cortisol and Competition Outcome}

To investigate differences between winners and losers in the variables investigated we used different approaches. Cortisol differences were analyzed by means of ANOVA for repeated measures. No effect of sampling time $(p>0.1)$ nor of the interaction $(p>0.1)$ were found while there was a statistically significant main effect of competition outcome, $\mathrm{F}_{1,44}=22.52, p<0.001, \eta_{p}^{2}=0.33$, indicating that athletes that lost the fight had overall higher levels of cortisol compared to winners. This difference seems to be driven by higher cortisol levels before the competition in those who went on to lose the fight $t(32.71)=5.19, p<0.001,95 \% C I[0.40 ; 0.92]$.

\section{Genotype, Outcome and Cortisol}

The distribution of the genotypes in our study population was 20 LL (43.50\%), 14 (30.50\%) LS and 12 SS (26.00\%). The relationship between genotype and competition outcome was analyzed by means of a likelihood ratio test (LRT): winners 


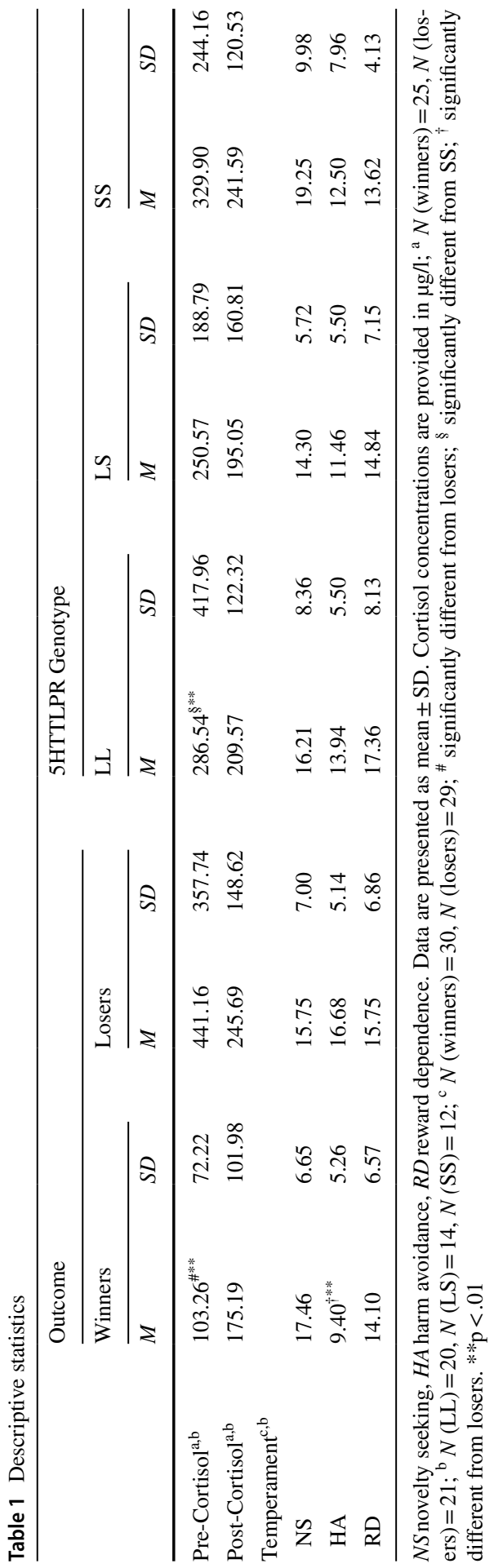


and losers did not differ in terms of genotypes, LR test $(3)=0.54, p>0.1$, Cramer's $\mathrm{V}=0.09$. Differences in cortisol response to competition between LL vs. SS genotypes were assessed using analysis of variance (ANOVA) for repeated measures followed by Student's t-test with Bonferroni adjustment. We focused our analysis on these two genotypes since the relationship between stress vulnerability and 5HTTLPR is stronger for SS homozygotes compared to LL (Way \& Taylor, 2010). A significant main effect of genotype, $\mathrm{F}_{1,30}=4.51, p<0.05, \eta_{p}^{2}=0.1$ was found but no effect of sampling time $(\mathrm{p}>0.1)$ nor of the interaction between genotype and sampling time $(p>0.1)$ were found, indicating that athletes homozygotes for the SS allele had overall higher levels of cortisol. This difference was already present before the competition, $t(28.57)=2.50, p=0.01,95 \% C I[0.01 ; 0.87]$.

\section{Relationship Between Temperament, Cortisol, Outcome and Genotype}

Differences between winners and losers in terms of temperament, were analyzed by means of a multivariate analysis of variance (MANOVA) followed up by univariate ANOVAs with Bonferroni adjustment. A statistically significant effect of competition outcome, $\mathrm{F}_{3,55}=10.46, p<0.0001$ was found. Univariate analysis of variance indicated that participants that lost the fight were characterized by higher scores of HA compared to winners, $\mathrm{F}_{1,57}=28.86, p<0.0001, \eta_{p}^{2}=0.33$. No statistically significant differences between genotypes were found for NS, HA and RD. Pre-competition but not post-competition levels of cortisol were positively correlated with HA, $r=0.47, p<0.001$ (Fig. 1), but no correlation was found with NS ( $r=-0.09$ ) or RD $(\mathrm{r}=0.11)$.

\section{Discriminant Analysis}

A forward stepwise discriminant analysis was used to identify the set of independent variables that clearly differentiate winners from losers. This was done using those independent variables that differed statistically in relation to competition outcome. The stepwise discriminant functional analysis was carried out entering harm avoidance in the first step and harm avoidance with pre-competition cortisol levels in the second step (see Table 2). This analysis showed that $80 \%$ of participants could be classified as winners or losers on the basis of their HA score. Adding the pre-competition cortisol levels in the regression (model II), shows that $85 \%$ of participants could be classified as winners or losers on the basis of their cortisol and HA scores.

\section{Discussion}

A crucial challenge for sport scientists is to identify the psychobiological substrates (i.e., personality, genes and hormones) that are associated with athletes' superior performance. Provided that sports are a ritualized form of competition evolved for access to primary and secondary fitness relevant resources, we expect successful athletes to show a cluster of functionally adapted traits. Natural selection should 


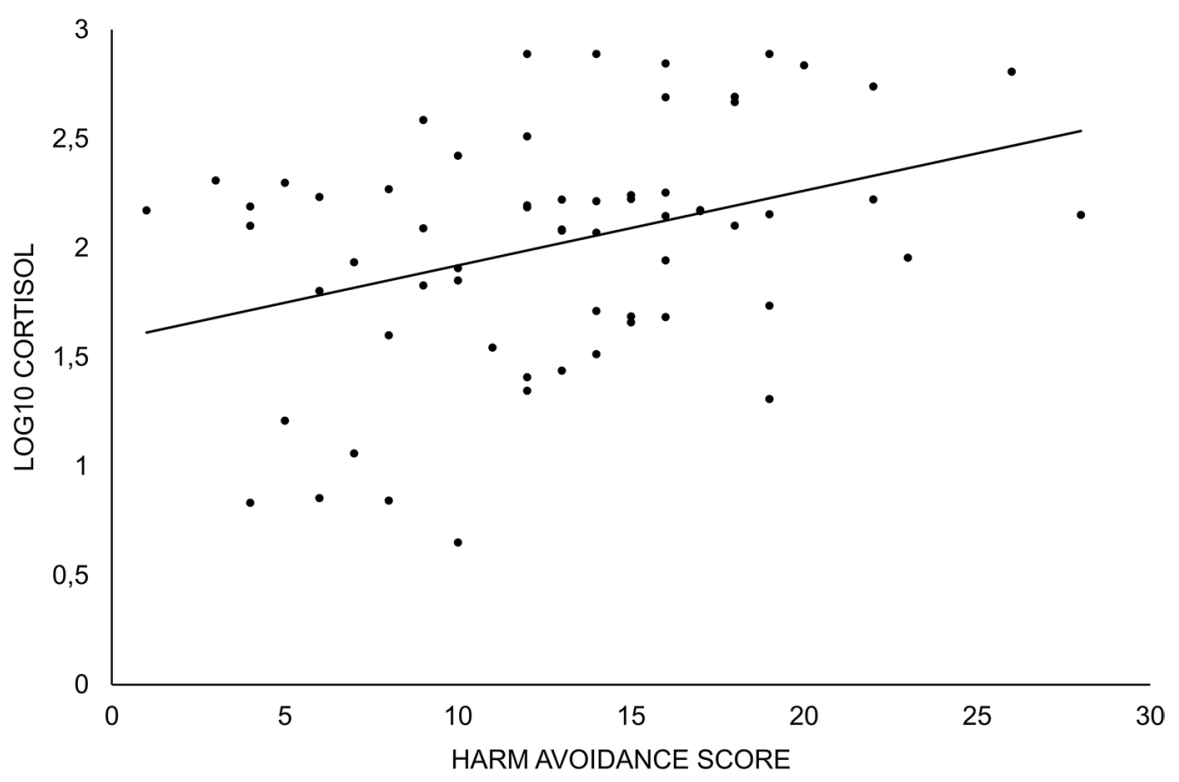

Fig. 1 Correlation between Harm Avoidance (HA) and pre-competition cortisol. Cortisol is measured in $\mu \mathrm{g} / \mathrm{l}$

favor the co-evolution of traits if their covariation has increased animals' performance throughout their evolutionary past. For example, if a specific type of personality is positively correlated with higher fitness, other traits that share the same genes, either through negative pleiotropy or linkage disequilibrium (Svensson et al., 2021) or physiological bases (Dochtermann, 2011; Kern et al., 2016; McGlothlin \& Ketterson, 2008) with the personality trait should be more frequently found in the same individual.

In the present study we were interested to know if winners and losers of a karate fight could be identified by their scores in three different psychobiological traits. We found that salivary cortisol levels $10 \mathrm{~min}$ before the competition were higher in athletes that lost the fight, but no differences were found between winners and losers for salivary cortisol reactivity. Athletes that lost the fight had on average higher levels of harm avoidance while no relationships of the 5HTTLPR polymorphism with competition outcome or harm avoidance were found. However, we provide preliminary evidence showing that athletes with the SS genotype might have on average higher pre-competition levels of salivary cortisol, an interesting insight in light of several studies reporting a role played by the 5HTTLPR polymorphism in managing sport anxiety (Petito et al., 2016, 2021; Sanhueza et al., 2016).

Within the animal literature, subjects that tend to win fights are characterized by a cluster of behavioral, physiological and neurobiological characteristics such as higher aggressiveness, higher risk-approach behavior and lower HPAA responses to challenges (Koolhaas et al., 1999; Korte et al., 2005). Currently, there is still an open debate on the role played by cortisol in predicting competition outcome in martial arts (Casto \& Edwards, 2016a; Filaire et al., 2009; Jiménez et al., 2012; Papacosta 


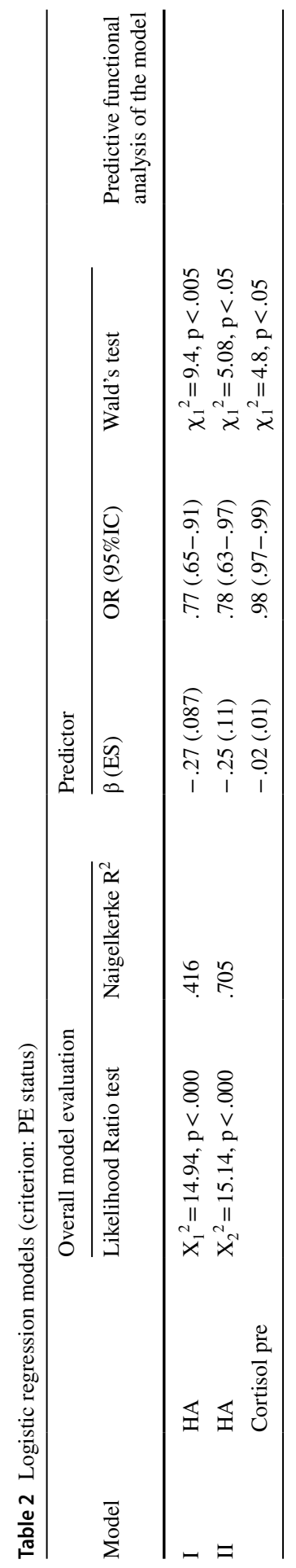


et al., 2016; Parmigiani et al., 2006, 2009; Salvador et al., 2003; Suay et al., 1999). Likewise, the role played by psychological factors such as mood and personality in relation to competition performance and especially on winning and losing has been extensively studied (Casanova et al., 2015; Casto \& Edwards, 2016b; Casto et al., 2017; Gonzalez-Bono et al., 1999; Salvador \& Costa, 2009; Salvador, 2005; Suay et al., 1999; Zilioli \& Watson, 2013), but a direct translation of the evolutionary concept of coping strategies and evolved, correlated traits such as personality and physiological responses has not yet been produced. Our finding that $85 \%$ of karate fighters could be predicted to be winners or losers based on their harm avoidance score and pre-competition cortisol levels is very interesting in his regard.

It is important to highlight that the single, pre-competition measure of cortisol of our study cannot unequivocally be considered an anticipatory response of the HPA axis to the competition. Instead, it possible that these higher levels of cortisol found in losers represent a stable trait of those people that experience higher everyday anxiety and stress because of their higher scores of harm avoidance. Some authors have suggested that elevated scores of harm avoidance may predispose individuals to experience psychological distress, fear, anxiety and low mood (Farmer \& Seeley, 2009; Trouillet \& Gana, 2008) and harm avoidance appears related with the magnitude of HPA axis activation (Tyrka et al., 2008). Thus, perhaps athletes that went on to lose the fight were already stressed out by similar daily hussles unrelated to the karate competition.

Lastly, the 5HTTLPR polymorphism was not predictive of victory or defeat nor of temperament, despite being correlated with pre-competition salivary cortisol. This should not be surprising for several reasons. We should not expect a single candidate gene to be predictive of competition outcome. Specifically in relation to behavioral coping strategies, genetic variation in genes related to other neurotransmitters such as dopamine may be important. In this regard, the dopamine transporter genotype 9/9 and allele 9 that have been reported to be highly frequent in Olympic athletes (Filonzi et al., 2015). However, the effects of candidate genes on personality (and perhaps on behavioral coping strategies) are probably very small, while the role played by many variants with small effects is more likely (Penke \& Jokela, 2016). Finally, it is possible that the lack of a correlation between harm avoidance and the $s$ allele could be due by the choice of the personality measure and by the lack of statistical power. In fact, the presence and strength of a SS genotype-anxiety link has been found to depend on the personality measures used and on sample size. For example, the neuroticism dimension of the Big Five personality inventory but not harm avoidance is strongly correlated with the 5HTTLPR polymorphism (Sen et al., 2004). Yet, the possible relationship between harm avoidance and the5HTTLPR polymorphism should not be discarded since a recent study carried out with high level Italian athletes reported that those with higher scores of harm avoidance were more likely to have the $s$ allele (Petito et al., 2021). Perhaps more important, the sample size of our study is a limitation for these kinds of research questions (Miller et al., 2013). 


\section{Conclusions}

In the present study we showed that pre-competition levels of cortisol were higher in amateur karate athletes that lost a competition compared to winners. The outcome of the competition was also associated with the temperamental scale of harm avoidance. This finding is a replication of previous studies suggesting that athletes with higher harm avoidance may be more vulnerable to psychological experiences influencing the HPA baseline activity. In turn, this may influence performance, possibly through psychological states that are related to harm avoidance such as anxiety. Moreover individual differences in the 5HTTLPR genotype of athletes may also play an important vulnerability role when in conjunction with harm avoidance.

We were able to correctly identify winners and losers based on their score of harm avoidance and their pre-competition cortisol levels. While the design of the present study does not allow us to shed light on the possibility that specific temperamental traits and endocrinological responses to stress are functionally related, from a theorical and empirical perspective our approach seems important for the following reasons: it could allow researchers to better characterize athletes in terms of attitude, performance; perhaps more importantly, it could allow to predict athletes' responses to the stress of competition and their well-being. We know from evolutionary biology that despite being advantageous, adaptive traits are not cost-free. Their costs are difficult to be clearly uncovered (Garland Jr, 2014), but are often observable in modern, mismatched environment (Palanza \& Parmigiani, 2016), as perhaps the current professional sports entertainment business. Thus, future work focusing on coping with sports challenges will certainly benefit from an evolutionary approach.

Supplementary Information The online version contains supplementary material available at https://doi. org/10.1007/s40750-021-00178-0.

Authors' Contributions Author DP analyzed the data and wrote the manuscript. Authors HD and LF collected the data; LF and FN conducted the genetic analyses; GC conducted the hormonal analyses; DP, HD and SP designed the study; PP and AP provided feedback on the study design, implementation and statistical analysis. All authors read and approved the final version of the manuscript.

Funding Open access funding provided by Università degli Studi di Parma within the CRUI-CARE Agreement.

Data Availability The data associated with the paper are available as supplementary data.

\section{Declarations}

Conflict of interest The authors declared that they have no conflict of interest

Open Access This article is licensed under a Creative Commons Attribution 4.0 International License, which permits use, sharing, adaptation, distribution and reproduction in any medium or format, as long as you give appropriate credit to the original author(s) and the source, provide a link to the Creative Commons licence, and indicate if changes were made. The images or other third party material in this article are included in the article's Creative Commons licence, unless indicated otherwise in a credit line to the material. If material is not included in the article's Creative Commons licence and your intended use is not permitted by statutory regulation or exceeds the permitted use, you will need to obtain permission directly from the copyright holder. To view a copy of this licence, visit http://creativecommons.org/licen ses/by/4.0/. 


\section{References}

Bartolomucci, A., Palanza, P., Sacerdote, P., Panerai, A. E., Sgoifo, A., Dantzer, R., \& Parmigiani, S. (2005). Social factors and individual vulnerability to chronic stress exposure. Neuroscience and Biobehavioral Reviews. https://doi.org/10.1016/j.neubiorev.2004.06.009

Behnke, M., \& Kaczmarek, L. D. (2018). Successful performance and cardiovascular markers of challenge and threat: A meta-analysis. International Journal of Psychophysiology, 130, 73-79. https://doi.org/10.1016/j.ijpsycho.2018.04.007

Blanchard, D. C., \& Blanchard, R. J. (2003). What can animal aggression research tell us about human aggression? Hormones and Behavior. https://doi.org/10.1016/S0018-506X(03)00133-8

Blascovich, J., Seery, M. D., Mugridge, C. A., Norris, R. K., \& Weisbuch, M. (2004). Predicting athletic performance from cardiovascular indexes of challenge and threat. Journal of Experimental Social Psychology, 40(5), 683-688. https://doi.org/10.1016/j.jesp.2003.10.007

Bramble, D. M., \& Lieberman, D. E. (2004). Endurance running and the evolution of Homo. Nature, 432(7015), 345-352. https://doi.org/10.1038/nature03052

Caramaschi, D., Carere, C., Sgoifo, A., \& Koolhaas, J. M. (2014). Neuroendocrine and autonomic correlates of animal personalities. Animal Personalities. https://doi.org/10.7208/chicago/97802 26922065.003 .0013

Casanova, N., Palmeira-De-Oliveira, Pereira, Crisóstomo, Travassos, B., Costa, A. M., \& Costa, A. M. (2015). Cortisol, testosterone and mood state variation during an official female football competition. In The Journal of sports medicine and physical fitness (Vol. 56, Issue 6). https://ubibl iorum.ubi.pt/handle/10400.6/7591

Casto, K. V., \& Edwards, D. A. (2016a). Before, during, and after: how phases of competition differentially affect testosterone, cortisol, and estradiol levels in women athletes. Adaptive Human Behavior and Physiology. https://doi.org/10.1007/s40750-015-0028-2

Casto, K. V., \& Edwards, D. A. (2016b). Testosterone, cortisol, and human competition. Hormones and Behavior. https://doi.org/10.1016/j.yhbeh.2016.04.004

Casto, K. V., Rivell, A., \& Edwards, D. A. (2017). Competition-related testosterone, cortisol, and perceived personal success in recreational women athletes. Hormones and Behavior, 92, 29-36. https://doi.org/10.1016/j.yhbeh.2017.05.006

Cintineo, H. P., \& Arent, S. M. (2019). Anticipatory salivary cortisol and state anxiety before competition predict match outcome in division I collegiate wrestlers. Journal of Strength and Conditioning Research, 33(11), 2905-2908. https://doi.org/10.1519/JSC.0000000000003376

Cloninger, C. R., Przybeck, T. R., \& Svrakic, D. M. (1991). The Tridimensional Personality Questionnaire: U.S. normative data. Psychological Reports, 69 (3 Pt 1), 1047-1057. https://doi.org/10.2466/ pr0.1991.69.3.1047

Çorak, A., Kapici, S., Sercan, C., Akkoç, O., \& Ulucan, K. (2017). A pilot study for determination of anxiety related SLC6A4 promoter "S" and "L" alleles in healthy Turkish athletes. Cellular and Molecular Biology. https://doi.org/10.14715/cmb/2017.63.5.6

Dochtermann, N. A. (2011). Testing Cheverud's conjecture for behavioral correlations and behavioral syndromes. Evolution, 65(6), 1814-1820. https://doi.org/10.1111/j.1558-5646.2011.01264.x

Farmer, R. F., \& Seeley, J. R. (2009). Temperament and character predictors of depressed mood over a 4-year interval. Depression and Anxiety. https://doi.org/10.1002/da.20459

Filaire, E., Alix, D., Ferrand, C., \& Verger, M. (2009). Psychophysiological stress in tennis players during the first single match of a tournament. Psychoneuroendocrinology. https://doi.org/10.1016/j.psyne uen.2008.08.022

Filaire, E., Maso, F., Sagnol, M., Ferrand, C., \& Lac, G. (2001). Anxiety, hormonal responses, and coping during a judo competition. Aggressive Behavior, 27(1), 55-63. https://doi.org/10.1002/10982337(20010101/31)27:1\%3c55::AID-AB5\%3e3.0.CO;2-H

Filonzi, L., Franchini, N., Vaghi, M., Chiesa, S., \& Marzano, F. N. (2015). The potential role of myostatin and neurotransmission genes in elite sport performances. Journal of Biosciences, 40(3), 531-537. https://doi.org/10.1007/s12038-015-9542-4

Garland, T., Jr. (2014). Trade-offs. Current Biology. https://doi.org/10.1016/j.cub.2013.11.036

Geary, D. C. (2016). Evolution of Sex Differences in Trait- and Age-Specific Vulnerabilities. Perspectives on Psychological Science, 11(6), 855-876. https://doi.org/10.1177/1745691616650677 
Gonzalez-Bono, E., Salvador, A., Serrano, M. A., \& Ricarte, J. (1999). Testosterone, cortisol, and mood in a sports team competition. Hormones and Behavior, 35(1), 55-62. https://doi.org/10.1006/hbeh. 1998.1496

Goodwin, G. F. (2008). Psychology in sports and the military: Building understanding and collaboration across disciplines. Military Psychology. https://doi.org/10.1080/08995600701804897

Hase, A., O’Brien, J., Moore, L. J., \& Freeman, P. (2019). The relationship between challenge and threat states and performance: A systematic review. Sport, Exercise, and Performance Psychology, 8(2), 123-144. https://doi.org/10.1037/spy0000132

Hruby, R., Nosalova, G., Monitor, S. H.-M. S., \& 2010, undefined. (2010). Predictive significance of TCI-R for antidepressant treatment. Medscimonit.Com. https://www.medscimonit.com/abstract/ indexMobile/idArt/881106

Jiménez, M., Aguilar, R., \& Alvero-Cruz, J. R. (2012). Effects of victory and defeat on testosterone and cortisol response to competition: Evidence for same response patterns in men and women. Psychoneuroendocrinology. https://doi.org/10.1016/j.psyneuen.2012.02.011

Jones, M., Meijen, C., McCarthy, P. J., \& Sheffield, D. (2009). A theory of challenge and threat states in Athletes. International Review of Sport and Exercise Psychology, 2(2), 161-180. https://doi.org/10. 1080/17509840902829331

Kern, E. M. A., Robinson, D., Gass, E., Godwin, J., \& Langerhans, R. B. (2016). Correlated evolution of personality, morphology and performance. Animal Behaviour, 117, 79-86. https://doi.org/10.1016/j. anbehav.2016.04.007

Koolhaas, J. M., Bartolomucci, A., Buwalda, B., de Boer, S. F., Flügge, G., Korte, S. M., Meerlo, P., Murison, R., Olivier, B., Palanza, P., Richter-Levin, G., Sgoifo, A., Steimer, T., Stiedl, O., van Dijk, G., Wöhr, M., \& Fuchs, E. (2011). Stress revisited: A critical evaluation of the stress concept. Neuroscience and Biobehavioral Reviews, 35(5), 1291-1301. https://doi.org/10.1016/j.neubiorev.2011. 02.003

Koolhaas, Jaap M., De Boer, S. F., Buwalda, B., \& Van Reenen, K. (2007). Individual variation in coping with stress: A multidimensional approach of ultimate and proximate mechanisms. Brain, Behavior and Evolution,. https://doi.org/10.1159/000105485

Koolhaas, J. M., Korte, S. M., De Boer, S. F., Van Der Vegt, B. J., Van Reenen, C. G., Hopster, H., De Jong, I. C., Ruis, M. A. W., \& Blokhuis, H. J. (1999). Coping styles in animals: Current status in behavior and stress- physiology. Neuroscience and Biobehavioral Reviews. https://doi.org/10.1016/ S0149-7634(99)00026-3

Korte, S. M., Koolhaas, J. M., Wingfield, J. C., \& McEwen, B. S. (2005). The Darwinian concept of stress: Benefits of allostasis and costs of allostatic load and the trade-offs in health and disease. Neuroscience and Biobehavioral Reviews. https://doi.org/10.1016/j.neubiorev.2004.08.009

Lombardo, M. P. (2012). On the evolution of sport. Evolutionary Psychology. https://doi.org/10.1177/ 147470491201000101

Lombardo, M. P., \& Deaner, R. O. (2018). On the evolution of the sex differences in throwing: Throwing is a male adaptation in humans. Quarterly Review of Biology, 93(2), 91-119. https://doi.org/10. $1086 / 698225$

Longman, D. P., Macintosh Murray, A., Roberts, R., Oakley, S., Wells, J. C. K., \& Stock, J. T. (2019). Ultra-endurance athletic performance suggests that energetics drive human morphological thermal adaptation. Evolutionary Human Sciences. https://doi.org/10.1017/ehs.2019.13

Longman, D. P., Murray, A., Roberts, R., Oakley, S., Wells, J. C. K., \& Stock, J. T. (2021). Energetics as a driver of human morphological thermal adaptation; evidence from female ultra-endurance athletes. Evolutionary Human Sciences. https://doi.org/10.1017/ehs.2021.17

Longman, D. P., Wells, J. C. K., \& Stock, J. T. (2020). Human athletic paleobiology; using sport as a model to investigate human evolutionary adaptation. Yearbook Phys Anthropol, 171, 42. https://doi. org/10.1002/ajpa.23992

Manfredonia, M. G., Gasperini, M., Sciuto, G., Bellodi, L., \& Smeraldi, E. (1991). The distribution of dimensional personality traits in an Italian general population. New Trends in Experimental and Clinical Psychiatry, 7(3), 113-129.

McGlothlin, J. W., \& Ketterson, E. D. (2008). Hormone-mediated suites as adaptations and evolutionary constraints. Philosophical Transactions of the Royal Society B: Biological Sciences, 363(1497), 1611-1620.

Meijen, C., Turner, M., Jones, M. V., Sheffield, D., \& McCarthy, P. (2020). A Theory of Challenge and Threat States in Athletes: A Revised Conceptualization. Frontiers in Psychology. https://doi.org/10. 3389/fpsyg.2020.00126 
Miller, R., Wankerl, M., Stalder, T., Kirschbaum, C., \& Alexander, N. (2013). The serotonin transporter gene-linked polymorphic region (5-HTTLPR) and cortisol stress reactivity: A meta-analysis. Molecular Psychiatry, 18(9), 1018-1024. https://doi.org/10.1038/mp.2012.124

Nonnis Marzano, F., Maldini, M., Filonzi, L., Lavezzi, A. M., Parmigiani, S., Magnani, C., Bevilacqua, G., \& Matturri, L. (2008). Genes regulating the serotonin metabolic pathway in the brain stem and their role in the etiopathogenesis of the sudden infant death syndrome. Genomics. https://doi.org/10. 1016/j.ygeno.2008.01.010

Otter, C., Huber, J., \& Bonner, A. (1995). Cloninger's tridimensional personality questionnaire: Reliability in an english sample. Personality and Individual Differences, 18(4), 471-480. https://doi.org/10. 1016/0191-8869(94)00199-3

Ouergui, I., Davis, P., Houcine, N., Marzouki, H., Zaouali, M., Franchini, E., Gmada, N., \& Bouhlel, E. (2016). Hormonal, Physiological, and Physical Performance During Simulated Kickboxing Combat: Differences Between Winners and Losers. International Journal of Sports Physiology and Performance. https://doi.org/10.1123/ijspp.2015-0052

Øverli, Ø., Sørensen, C., Pulman, K. G. T., Pottinger, T. G., Korzan, W., Summers, C. H., \& Nilsson, G. E. (2007). Evolutionary background for stress-coping styles: Relationships between physiological, behavioral, and cognitive traits in non-mammalian vertebrates. Neuroscience and Biobehavioral Reviews. https://doi.org/10.1016/j.neubiorev.2006.10.006

Palanza, P., \& Parmigiani, S. (2016). Why human evolution should be a basic science for medicine and psychology students. Jass Proceeding Paper Journal of Anthropological Sciences, 94, 183-192. https://doi.org/10.4436/jass.94034

Papacosta, E., Nassis, G. P., \& Gleeson, M. (2016). Salivary hormones and anxiety in winners and losers of an international judo competition. Journal of Sports Sciences, 34(13), 1281-1287. https://doi.org/ 10.1080/02640414.2015.1111521

Parmigiani, S., Bartolomucci, A., Palanza, P., Galli, P., Rizzi, N., Brain, P. F., \& Volpi, R. (2006). In judo, Randori (free fight) and Kata (highly ritualized fight) differentially change plasma cortisol, testosterone, and interleukin levels in male participants. Aggressive Behavior, 32(5), 481-489. https://doi. org/10.1002/ab.20148

Parmigiani, S., Dadomo, H., Bartolomucci, A., Brain, P. F., Carbucicchio, A., Costantino, C., Ferrari, P. F., Palanza, P., \& Volpi, R. (2009). Personality traits and endocrine response as possible asymmetry factors of agonistic outcome in karate athletes. Aggressive Behavior, 35(4), 324-333. https://doi.org/ 10.1002/ab.20306

Penke, L., \& Jokela, M. (2016). The evolutionary genetics of personality revisited. Current Opinion in Psychology, 7, 104-109. https://doi.org/10.1016/j.copsyc.2015.08.021

Petito, A., Altamura, M., Iuso, S., Padalino, F. A., Sessa, F., D’Andrea, G., Margaglione, M., \& Bellomo, A. (2016). The relationship between personality traits, the 5HTT polymorphisms, and the occurrence of anxiety and depressive symptoms in elite athletes. PLoS One. https://doi.org/10.1371/journ al.pone.0156601

Petito, A., D’Andrea, G., Sessa, F., Fortunato, F., Iannelli, G., Bellomo, A., ... \& Iuso, S. (2021). Harm avoidance as a possible mediator in the relationship between the 5-HTTLPR and cognitive anxiety in high level athletes. Mediterranean Journal of Clinical Psychology, 9(1). https://doi.org/10.6092/ 2282-1619/mjcp-2757

Quilty, L. C., Godfrey, K. M., Kennedy, S. H., \& Bagby, R. M. (2010). Harm avoidance as a mediator of treatment response to antidepressant treatment of patients with major depression. Psychotherapy and Psychosomatics, 79(2), 116-122. https://doi.org/10.1159/000276372

Reardon, C. L., Hainline, B., Miller Aron, C., Baron, D., Baum, A. L., Bindra, A., Budgett, R., Campriani, N., Mauricio Castaldelli-Maia, J., Currie, A., Lee Derevensky, J., Glick, I. D., Gorczynski, P., Gouttebarge, V., Grandner, M. A., Hyun Han, D., Sills, A., Stull, T., Swartz, L., \& Jing Zhu, L. (2019). Mental health in elite athletes: International Olympic Committee consensus statement (2019) Consensus statement. British Journal of Sports Medicine, 53, 30. https://doi.org/10.1136/ bjsports-2019-100715

Rossi, A., Struzzi, P., Daneluzzo, E., Spaziani, D., Bustini, M., Prosperini, P., et al. (1996). La quarta dimensione del Tridimensional Personality Questionnaire (TPQ): studio di validazione della versione italiana. Giornale Italiano Di Psicopatologia, 3, 260-266.

Salvador, Alicia. (2005). Coping with competitive situations in humans. Neuroscience and Biobehavioral Reviews, 29(1), 195-205. https://doi.org/10.1016/j.neubiorev.2004.07.004 
Salvador, Alicia, \& Costa, R. (2009). Coping with competition: Neuroendocrine responses and cognitive variables. Neuroscience and Biobehavioral Reviews, 33(2), 160-170. https://doi.org/10.1016/j.neubi orev.2008.09.005

Salvador, A., Suay, F., González-Bono, E., \& Serrano, M. A. (2003). Anticipatory cortisol, testosterone and psychological responses to judo competition in young men. Psychoneuroendocrinology, 28(3), 364-375. https://doi.org/10.1016/S0306-4530(02)00028-8

Sanhueza, J. A., Zambrano, T., Bahamondes-Avila, C., \& Salazar, L. A. (2016). Association of anxietyrelated polymorphisms with sports performance in Chilean long distance triathletes: A pilot study. Journal of Sports Science and Medicine, 15(4), 554-561.

Sapolsky, R. M., Romero, L. M., \& Munck, A. U. (2000). How do glucocorticoids influence stress responses? Integrating permissive, suppressive, stimulatory, and preparative actions. Endocrine Reviews, 21(1), 55-89.

Sen, S., Burmeister, M., \& Ghosh, D. (2004). Meta-analysis of the association between a serotonin transporter promoter polymorphism (5-HTTLPR) and anxiety-related personality traits. American Journal of Medical Genetics, 127B(1), 85-89. https://doi.org/10.1002/ajmg.b.20158

Sgoifo, A., Costoli, T., Meerlo, P., Buwalda, B., Pico'-Alfonso, M. A., De Boer, S., Musso, E., \& Koolhaas, J. (2005). Individual differences in cardiovascular response to social challenge. Neuroscience and Biobehavioral Reviews. https://doi.org/10.1016/j.neubiorev.2004.07.001

Shaw, C. N., \& Stock, J. T. (2009). Habitual throwing and swimming correspond with upper limb diaphyseal strength and shape in modern human athletes. Wiley Online Library, 140(1), 160-172. https:// doi.org/10.1002/ajpa.21063

Slimani, M., Paravlic, A. H., Chaabene, H., Davis, P., Chamari, K., \& Cheour, F. (2018). Hormonal responses to striking combat sports competition: A systematic review and meta-analysis. Biology of Sport, 35(2), 121-136.

Suay, F., Salvador, A., González-Bono, E., Sanchís, C., Martínez, M., Martínez-Sanchis, S., Simón, V. M., \& Montoro, J. B. (1999). Effects of competition and its outcome on serum testosterone, cortisol and prolactin. Psychoneuroendocrinology, 24(5), 551-566. https://doi.org/10.1016/S0306-4530(99) 00011-6

Svensson, E. I., Arnold, S. J., Bürger, R., Csilléry, K., Draghi, J., Henshaw, J. M., Jones, A. G., De Lisle, S., Marques, D. A., McGuigan, K., Simon, M. N., \& Runemark, A. (2021). Correlational selection in the age of genomics. Nature Ecology and Evolution (Vol. 5, pp. 562-573). Nature Research.

Sysoeva, O. V., Maluchenko, N. V., Timofeeva, M. A., Portnova, G. V., Kulikova, M. A., Tonevitsky, A. G., \& Ivanitsky, A. M. (2009). Aggression and 5HTT polymorphism in females: Study of synchronized swimming and control groups. International Journal of Psychophysiology. https://doi.org/10. 1016/j.ijpsycho.2008.12.005

Trouillet, R., \& Gana, K. (2008). Age differences in temperament, character and depressive mood: A cross-sectional study. Clinical Psychology and Psychotherapy. https://doi.org/10.1002/cpp.580

Tyrka, A. R., Wier, L. M., Price, L. H., Rikhye, K., Ross, N. S., Anderson, G. M., Wilkinson, C. W., \& Carpenter, L. L. (2008). Cortisol and ACTH responses to the Dex/CRH Test: Influence of temperament. Hormones and Behavior, 53(4), 518-525. https://doi.org/10.1016/j.yhbeh.2007.12.004

Way, B. M., \& Taylor, S. E. (2010). The serotonin transporter promoter polymorphism is associated with cortisol response to psychosocial stress. Biological Psychiatry. https://doi.org/10.1016/j.biopsych. 2009.10.021

Wilcox, R. R. (2010). Fundamentals of modern statistical methods: Substantially improving power and accuracy. In R. R. Wilcox (Ed.), Fundamentals of modern statistical methods: Substantially improving power and accuracy. Springer.

Zilioli, S., \& Watson, N. V. (2013). Winning isn't everything: mood and testosterone regulate the cortisol response in competition. PLoS One, 8(1), 52582. https://doi.org/10.1371/journal.pone.0052582

Publisher's Note Springer Nature remains neutral with regard to jurisdictional claims in published maps and institutional affiliations. 


\section{Authors and Affiliations}

Davide Ponzi ${ }^{1}$ D $\cdot$ Harold Dadomo ${ }^{1} \cdot$ Laura Filonzi $^{2} \cdot$ Paola Palanza ${ }^{1}$. Annalisa Pelosi ${ }^{1}$. Graziano Ceresini ${ }^{1}$ - Stefano Parmigiani ${ }^{2}$. Francesco Nonnis Marzano ${ }^{2}$

$\triangle$ Davide Ponzi

davide.ponzi@unipr.it

1 Department of Medicine and Surgery, University of Parma, Parco Area delle Scienze 11A, 43124 Parma, Italy

2 Unit of Evolutionary and Functional Biology, Department of Chemistry, Life Sciences and Environmental Sustainability, University of Parma, Parma, Italy 